\title{
Para una CRítica de la Violencia en PSiCOANÁlisis: De la VIOLENCIA ORIGINARIA DE LA LEY A SU TRAMITACIÓN TRÁGICA
}

\author{
José Cabrera Sánchez ${ }^{1}$
}

\begin{abstract}
Resumen: Para Freud la relación entre violencia y ley parece indisociable, en tanto la instauración de esta última depende de una violencia inaugural (el asesinato del padre), la que en lugar de quedar limitada a este momento inicial continúa activa a través de los propios mecanismos psíquicos que encarnan la función de la ley, de manera tal que la ley se encuentra coludida permanentemente con la misma violencia que intenta regular. Pensamos que este dilema es equivalente al delimitado por Benjamin en Para una crítica de la violencia, ensayo en el que este propone, por medio de la figura de la violencia divina o pura, una vía para interrumpir el papel fundante y conservador de la ley que le cabría a la violencia mítica. Se propone que la interpretación de Lacan sobre el acto de Antígona

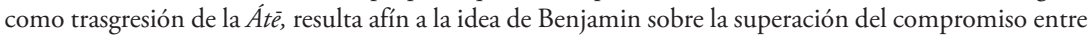
violencia mítica y ley que adjudica al acontecimiento de la violencia pura, replicando una crítica a la violencia, esta vez dentro de los márgenes teóricos del psicoanálisis. En ambos casos resulta posible situar un más allá del compromiso entre violencia y ley, el cual permite pensar una refundación de los límites simbólicos que dan soporte a la vida en comunidad.
\end{abstract}

Palabras Clave: Ley. Crítica de la violencia. Benjamin. Psicoanálisis. Antígona.

\section{INTRODUCCIÓN}

¿Es la figura de la ley aquello que encarna el más eficaz límite cultural a la violencia, o esta no es sino el modo más refinado en que la violencia continúa operando con la fuerza irrestricta que le confiere su institucionalidad? Parece bastante claro que el psicoanálisis puede responder afirmando que no hay

\footnotetext{
${ }_{1}^{1}$ Profesor del Instituto de Psicología, Universidad Austral de Chile, Puerto Montt - Chile. ID https:// orcid.org/0000-0002-4463-9741 E-mails: jose.cabrera@uach.cl, jcabrera@spm.uach.cl

Psicólogo, Doctor en Psicoanálisis. Sus líneas de trabajo exploran los vínculos entre psicoanálisis y filosofía, el trauma histórico y la memoria colectiva. Investigador responsable proyecto FONDECYTIniciación No11180424 "Elaboración del trauma psicosocial transgeneracional en víctimas de la dictadura chilena: la experiencia testimonial y la construcción de memoria colectiva en el contexto del proyecto de museo de la memoria de Puerto Montt".
}

http://dx.doi.org/10.1590/0101-3173.2019.v42n1.06.p101

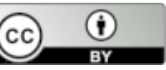

This is an open-access article distributed under the terms of the Creative Commons Attribution License. 
disyunción entre la ley como límite a la violencia y la ley como encarnación institucionalizada de la violencia, cuestión que no deja de ser problemática.

Las conclusiones a las que arriba Freud (1990) en El malestar en la cultura dan cuenta del precio que pagamos por la pacificación de nuestros apetitos para poder sostener alguna forma de vínculo social. Para Freud la morigeración de la violencia hacia el semejante que se sigue de la entrada en funcionamiento del superyó -uno de los argumentos centrales de El malestar en la cultura- no debe ser interpretada como un triunfo del avance civilizatorio sobre la brutalidad de la naturaleza; la incómoda constatación de Freud es que el desarrollo de la cultura es correlativo al incremento de una violencia autoimpuesta bajo la forma de los ideales. Así, mientras más se avanza en el refinamiento moral, más aumenta la crueldad de las demandas del ideal del yo (FREUD, 1992a), fenómeno que hace manifiesta la vigencia de la violencia a la que se pretendía poner límite.

La genealogía de la cultura establecida por Freud se organiza según una economía de la culpabilidad (ASSOUN, 2003), la que asegura un reflujo de la violencia inaugural bajo la forma del apego a la ley. Esta reconfiguración de la destructividad hace posible la convivencia, tal como el paso del estado de naturaleza a una sociedad regulada por un contrato instituyente torna viable la comunidad, pero, tanto para Freud como para Hobbes, esto no significa que la violencia haya sido depurada, por el contrario, ahora se encuentra destilada hasta obtener la transparencia de la ley.

Ahora bien ipodría pensarse una forma de la ley que efectivamente se distancie de la violencia a la que busca poner límite? De otra forma, la comprensión psicoanalítica de la ley no logrará escapar a la lógica de la repetición que, aunque estilizada bajo la forma de la norma, nos sigue remitiendo a una violencia originaria y mítica. Freud dice que lo no recordado no se pierde sino que se repite, y que el recuerdo y la elaboración son el trabajo necesario para poner límite a la reproducción compulsiva del pasado (FREUD, 1991a), repetición que se nos presenta como aún más loca cuando nos damos cuenta que su estructura está más allá del principio de placer.

Buscar una salida al impasse que hemos delineado nos aproxima a la vía trazada por Benjamin en su célebre ensayo Para una crítica de la violencia (BENJAMIN, 1998), en tanto nuestra inquietud se entronca con la misma pregunta que orientó la reflexión del filósofo alemán; de tal forma, creemos que se requiere efectuar una crítica de la violencia en psicoanálisis en el mismo 
sentido en que Benjamin se la planteó, es decir, interrogándonos sobre la posibilidad de encontrar una forma de interrupción genuina de la violencia que tanto funda como conserva la ley.

\section{TóTEM Y TABÚ, EL ORIGEN PROBLEMÁTICO DE LA LEY}

Es de sobra conocido el argumento de Tótem y tabú (FREUD, 1991b), del cual recordaremos que en lo esencial nos remite a un momento previo a la cultura, en el que los seres humanos se organizaban en clanes familiares dominados por el padre de la horda, quien acaparaba el acceso a las mujeres, matando, castrando o expulsando a los hijos varones que desafiaran su poder; en cierto momento los hermanos, aliando sus fuerzas, destronan al padre, al cual dan muerte. Con posterioridad a la muerte del padre, los hijos se ven asaltados por el remordimiento y la culpa, lo que da cuenta de la ambivalencia afectiva que los ligaba a este; dicho remordimiento los conduce a buscar una forma de reparación que desemboca en la construcción del tótem, figura que viene a sustituir simbólicamente al padre, y a la que se le atribuyen en definitiva las mismas normas y prohibiciones que el primero imponía. De tal forma, la institución del totemismo tendrá dos consecuencias que pueden ser pensadas como constitutivas del tránsito entre naturaleza y cultura: las prohibiciones del incesto y del homicidio. La primera de estas interdicciones se deduce directamente del carácter sustitutivo del tótem respecto del padre, en tanto su presencia evoca la imposibilidad de acceder a las mujeres del clan tal como aquel lo mandaba; por otro lado, si el tótem ha sido constituido en respuesta a la culpa por el asesinato del padre, otro de los mandatos que de él se derivan es la prohibición de dar muerte al animal totémico, ya que este no es sino una representación del padre. La interdicción de dar muerte al animal totémico se extenderá posteriormente a los hermanos de la horda, constituyendo el fundamento de la prohibición del asesinato. Hay que reparar en que la prohibición del homicidio se sigue del tabú del incesto, ya que la limitación de la agresión persigue mantener vacío el lugar del padre, de manera tal que la igualdad entre los hermanos no es natural, sino que se sustenta en una equivalencia establecida por convención entre ellos, y cuyo fin es la suspensión indefinida de la posesión de las mujeres del clan. Este punto es de gran relevancia, ya que permite distinguir que la propuesta freudiana del proceso de instauración de la ley se distancia de los principios del positivismo jurídico (BOBBIO, 1992; HART, 1994; KELSEN, 1979), para el cual no existe una conexión necesaria entre derecho y moral, y que además supone un 
fundamento racional que justifica la implementación de la ley. En la propuesta freudiana lo que no debe perderse de vista es que los hermanos al prohibirse el asesinato no lo hacen movidos por la racionalidad que supone evitar la amenaza constante del semejante, sino por efecto de la culpa que los domina, y, en este sentido, la inicial limitación de la violencia es atribuida por Freud a principios que no pueden denominarse más que morales, ya que se sustentan no en el intento de limitar el uso de la fuerza bruta que alguna vez se arrogó el padre, sino en la exterioridad mítica en que este último devino tras su asesinato. La ley no surge entonces desde el acuerdo interno a la comunidad de los hermanos, sino que aparece cuando el padre es representado por el tótem, un objeto superior y fuera del alcance de un contrato que dote de una inteligibilidad racional a la ley.

Hemos indicado que el tótem se ubica en una condición de exterioridad respecto de la comunidad, lo que debe ser comprendido en el sentido de que una vez que este es instituido queda fuera del alcance de la colectividad, en una posición que no puede someterse al juicio o arbitrio del propio grupo que construyó la mitología que le otorga validez. La función reguladora del tótem parece acercarse a la idea de excepción soberana (AGAMBEN, 2006), en tanto la ley totémica se presenta como una ley que presupone lo no jurídico como un fundamento que perdura en la interioridad de la norma: el tótem encierra una doble significación contradictoria, ya que prohíbe pero al mismo tiempo rememora el crimen que funda la organización de la comunidad de los hermanos; en el sentido recién expuesto, la institución totémica responde a una organización legal que opera según una lógica de exclusión-incluyente, en tanto testimonia sobre la ineluctable presencia de lo que se supone expulsado del orden social. La operación de la ley totémica remite a la necesidad de la violencia criminal en el origen de la ley, al tiempo que hace manifiesta la perdurabilidad de dicha violencia bajo la forma de la culpa y los principios morales que dan sostén a la ley. Pero además, la ley totémica atestigua sobre otra forma de exclusión-incluyente, ya que una vez que el tótem ha sido instaurado opera incluyendo a todos bajo su función, pero resulta un principio excluido al arbitrio o debate de la comunidad, y, de tal forma, puede ser considerado como una exterioridad que resulta incluida a través de la forma de la interdicción.

En la versión freudiana, la ley más que ser aceptada, se impone violentamente, pero, y he aquí lo fundamental, esta imposición no proviene desde afuera -el padre ya no es una figura efectiva de la realidad-sino desde la 
experiencia interiorizada de la culpa. La culpa pervive con independencia de la real brutalidad del padre, transformando la agresión natural pre-cultural en un motivo moral que no solo empuja a la obediencia, sino que metaboliza la ferocidad de la fuerza paterna en violencia con fuerza de ley.

Más de diez años después de escribir Tótem y tabú, Freud presenta la propuesta conceptual que da forma definitiva al superyó (FREUD, 1992b), organización teórica que deja ver una serie de nexos con las ideas expuestas en el estudio de carácter antropológico que le precedió. El yo y el ello, un texto calificable como clínico y metapsicológico, no es ajeno a juicios que se extienden, tal como en Tótem y tabú, hacia el terreno de la vida cultural, como queda de manifiesto en la siguiente cita:

Mientras más un ser humano sujete su agresión, tanto más aumentará la inclinación de su ideal a agredir a su yo. Es como un descentramiento \{desplazamiento\}, una vuelta \{re-volución\} hacia el yo propio. Ya la moral normal, ordinaria, tiene el carácter de dura restricción, de prohibición cruel. Y de ahí proviene, a todas luces, la concepción de un ser superior inexorable en el castigo. (FREUD, 1992b, p. 55).

De la cita precedente lo que nos interesa destacar es la referencia de Freud a una exterioridad a la que se le atribuye la crueldad de la prohibición, la que coincide con la función social del tótem; es como si a pesar del trabajo civilizatorio perdurara en el hombre un soporte mítico de la ley, lo que supone que el apego moral a la ley no descansa en la autonomía de la responsabilidad, sino en la relación de dependencia respecto de ese "ser superior inexorable en el castigo". Si esa exterioridad mítica, encarnada ya sea en el tótem o en el superyó, no es otro que el padre, entonces el apego a la ley vía la culpa, no hace más que repetir, desplazadamente y bajo la forma del castigo, la violencia que en un momento se dirigió al padre. Una concepción de la ley de esta naturaleza resulta problemática ya que expone que la estructura íntima de la ley y la acción moral están organizadas por una violencia que no es solo instauradora sino que coextensiva a su operación y mantención, en otras palabras, el avance cultural o la sofisticación psíquica no escapan al imperio de una violencia que se reproduce en el mismo movimiento que pretende domeñarla y que continúa rindiendo culto al acto inaugural que la instauró: la muerte del padre. 


\section{Del Tótem AL SOPORTE FANTASMÁTICO DEL DESEO}

La ficción científica de Freud adolece de una debilidad que fue indicada desde la propia antropología, nos referimos a la crítica al totemismo expuesta por Lévi-Strauss (1998).

Lévi-Strauss señala que, contrariamente a lo afirmado por Freud, no se registra en todas las sociedades un vínculo directo entre el totemismo y la prohibición del incesto, pero es posible establecer que la interdicción del incesto es la regla fundamental que instaura el umbral entre naturaleza y cultura, y a la cual sí resulta atribuible un carácter universal. El problema que la aserción de Lévi-Strauss genera para la teoría freudiana del origen de la ley es que desliga la constitución de la cultura del acto homicida que Freud sitúa como momento instituyente, lo que trae consigo el cuestionamiento a toda la arquitectura conceptual que liga asesinato, ambivalencia y culpa como soportes estructurales del origen y apego a la ley.

Sin embargo, el cuestionamiento de Lévi-Strauss comporta una posibilidad para pensar una relación distinta entre violencia y ley en psicoanálisis, opción que surge al situar la hipótesis freudiana en el estatuto del mito, y como tal, de una ficción cuyo fundamento no debe ser buscado en algún acontecimiento efectivo, sino que debe ser concebido como fundado en un deseo capaz de movilizar los mecanismos ficcionales que dan forma a una fantasía de los orígenes, la que es ubicada retroactivamente, según la lógica de la Nachträglichkeit, en el umbral entre naturaleza y cultura; en este sentido, el mito totémico no es la conmemoración de un evento instituyente, sino una fantasía que surge como respuesta a un deseo siempre correlativo a su prohibición. Comprender el mito totémico como la manifestación de una fantasía supone asumir que la relación entre violencia y ley expresa un deseo y que, por lo tanto, su origen se conjuga siempre en tiempo presente. Es como si Lévi-Strauss hiciera suya la teoría de la realidad psíquica y le recordara a Freud que debía abandonar también la teoría del trauma real en lo que compete a sus reflexiones culturales, de manera tal que la hipótesis antropológica del asesinato del padre se muestre como lo que realmente es, a saber, una manifestación simbólica de deseo. Al respecto Lévi-Strauss (1998, p. 569) señala:

El deseo de la madre o de la hermana, el asesinato del padre y el arrepentimiento de los hijos, sin duda no corresponden a un hecho o un conjunto de hechos que ocupan en la historia un lugar determinado. Pero traducen tal vez, bajo forma simbólica, un sueño a la vez perdurable y antiguo, y el prestigio de ese sueńo, su poder para modelar los pensamientos 
de los hombres a pesar de ellos, proviene precisamente del hecho de que los actos que evoca jamás fueron realizados porque la cultura se opuso a ello, siempre y en todas partes. Las satisfacciones simbólicas a las que se inclina, según Freud, la nostalgia del incesto, no constituyen entonces la conmemoración de un acontecimiento. Son otra cosa y más que eso: son la expresión permanente de un deseo de desorden o más bien de contraorden.

La crítica de Lévi-Strauss nos conduce a asumir que la especulación freudiana tiene la estructura de un mito, es decir, Tótem y tabú debe ser interpretado como la construcción retroactiva de una fantasía que expone la verdad del deseo, una realidad que se sostiene en su pura facticidad simbólica. El que no exista un acontecimiento histórico que opere como un punto de referencialidad concreta que ate la ley a un acto de violencia instauradora, podría suponer una posibilidad de que la lógica de la ley para el psicoanálisis se vea depurada de una necesaria y continua filiación con la violencia, no simplemente por la vía de negar la existencia de un crimen originario con el que la ley se encuentra coludida, sino por la senda propiamente psicoanalítica del cuestionamiento y desmontaje del deseo que se expresa y sostiene a través de tal escenificación mítica.

Lévi-Strauss indica que la fantasía de origen, en que se amalgaman asesinato e incesto, es la manifestación de un deseo de desorden o contraorden, lo que implica que el mito viene a responder como una solución de compromiso en la medida de que expone una doble y simultánea significación: aquello que es prohibido y al mismo tiempo anhelado. El tabú, forma primigenia de la ley, es caracterizado por Freud por su ambivalencia, de manera que expone bajo la forma de la prohibición aquello que es más deseado; el tabú entonces no conmemora el momento de entrada en vigencia de la prohibición, sino que hace presente, mediante el recurso de una remisión al pasado, un deseo que sigue siendo de una actualidad acuciante.

Si el mito no es otra cosa que una fantasía retroactivamente construida, y que como tal sirve de sustento a un determinado deseo, entonces la complicidad entre ley y violencia en psicoanálisis podría ser tramitada a través de procedimientos internos al propio psicoanálisis. $\mathrm{Al}$ asumir que el objetivo de un análisis es el atravesamiento del fantasma o fantasía fundamental (LACAN, 2010, 2012), podríamos esperar que el trabajo de interrogación del deseo permita un desmontaje del soporte fantasmático de la ley, lo que supone una reconfiguración del enlace que parece amarrar ley y violencia de manera 
indisoluble. Si el psicoanálisis quiere sostener una crítica de la violencia no puede seguir afirmando la inmutabilidad del vínculo entre ley y violencia, sino asumir que esta alianza expresa una particular configuración del deseo. Lo que Freud ofrece en Tótem y tabú no es entonces una crónica o reconstrucción del acontecimiento instituyente en que ley y violencia se funden, sino que expone narrativamente la estructura de lo que podríamos llamar un "deseo de ley». Si Lévi-Strauss está en lo correcto, la proposición de Tótem y tabú no expone una relación necesariamente indisociable entre violencia y ley, sino más bien un deseo en que violencia y ley se presentan enlazados a través de una fantasía que opera como un origen imaginario, lectura que abre una opción para pensar, dentro de los márgenes del psicoanálisis, una crítica a la aparentemente inherente violencia de la ley.

\section{VIOLENCIA Y LEY: UNA CRÍTICA}

Finalizamos la sección anterior señalando la posibilidad para el psicoanálisis de encontrar, a través de sus procedimientos interpretativos, una disyunción de la relación entre violencia y ley; intentaremos mostrar que esta posibilidad podría resultar afín a la propuesta de Benjamin en Para una crítica de la violencia.

Al comienzo del ensayo del filósofo alemán nos encontramos con una definición significativa del terreno en el que este se moverá, foco interpretativo que queda claramente establecido en la siguiente afirmación: "La violencia sólo puede encontrarse en el dominio de los medios y no en el de los fines." (BENJAMIN, 1998, p. 23).

El contrapunto entre derecho natural y derecho positivo conduce a Benjamin a señalar que la diferencia entre ellos es que el derecho natural sostiene la legitimidad de la violencia en acuerdo a los fines que ella permita alcanzar, en tanto el derecho positivo juzga la legitimidad de los medios que permiten alcanzar los fines de la justicia; esta distinción le permite a Benjamin de entrada trazar una delimitación: el problema central al que debe atenerse una crítica de la violencia es el de la legitimidad de la violencia en tanto medio. Este punto de corte inicial lo lleva a descartar el jusnaturalismo, en la medida de que este es ciego respecto del condicionamiento de los medios; la teoría positiva será entonces el punto de apoyo para la evaluación de Benjamin, ya que la que considera capaz de hacer una "distinción [que] se centra en la violencia históricamente reconocida, sancionada o no.” (BENJAMIN, 1998, 
p. 25). El análisis de dos clases de eventos emplazados concretamente en la historia, la huelga y la guerra, le permiten a Benjamin dar cuenta de la doble función de la violencia (su doble trabajo de mediación) en su relación a la ley: por una parte como condición de instauración, y por otra de conservación del derecho. El problema de la constatación de la circularidad de la violencia como medio, dado que funda y conserva la ley, es la dificultad que esto supone para situar a la violencia como un instrumento de subversión del ordenamiento jurídico, en tanto parece impotente para refundar las relaciones entre los hombres a partir del advenimiento de una nueva forma de ley. Esta clausura de la violencia dentro del circuito de la creación y conservación de la ley, hace que el derecho positivo opere como si existiese una condición de garantía que valida su hegemonía sobre la violencia, con lo cual se ve anulado el carácter de objeto cultural e históricamente creado que debería caracterizar a la ley.

El derecho positivo, aun cuando es conceptualmente capaz de reconocer la constitución histórica de la ley, queda atrapado en su tendencia a la conservación, movimiento que lo conduce a hegemonizar el control de la violencia, haciendo que la medialidad de esta última solo resulte válida dentro de los marcos de la ley en vigencia, de modo tal que la renovación del derecho resulta anulada en tanto la irrupción de una nueva violencia fundadora es rechazada al ser catalogada como impropia dentro del orden establecido. La enajenación de la violencia por parte del derecho positivo se traduce en que la condición de contingencia e indeterminación de la ley se ve anulada, dado que, para la propia ley, sería amenazante reconocer que su origen dependió de una violencia previa a su entrada, acontecimiento fundante que problematiza la validez de la violencia legal puesta al servicio de la conservación del orden jurídico. La problemática contingencia de la ley es cancelada por medio de una singular torsión de la consciencia de la ley sobre sí misma, ya que el derecho, para poder perpetuarse, se sirve de un recurso que se opone precisamente a la indeterminación del evento que lo funda: "El sentido más profundo de la indeterminación del orden de derecho se hará patente más adelante, cuando se considere la esfera del destino de donde deriva." (BENJAMIN, 1998, p. 31). La ley apela, para autorizar su uso de la violencia, a "un orden fatalmente necesario" (BENJAMIN, 1998, p. 30), el cual Benjamin hace equivaler al destino. La introducción del destino como validación de la violencia funciona como un principio de predestinación que paraliza la crítica histórica de la violencia y borra cualquier opción de pensarla en una relación diversa con la ley, es decir, más allá de su carácter fundador y conservador. 
En el ensayo de Benjamin el uso del término destino debe ser interpretado en el sentido de la predestinación o Ananké, un principio ineludible que determina el decurso de la ley. Las referencias de Benjamin se presentan investidas de una semántica cargada de misticismo, por ejemplo cuando toma a la pena de muerte como prototipo de la inclusión de un orden ineludible en el lazo que une ley y violencia: "Si bien la razón es incapaz de decidir sobre la legitimidad de medios y la justicia de fines, siendo más bien una violencia fatal la que los determina, por encima de ella, lo hace Dios." (BENJAMIN, 1998, p. 38). Y es este factor místico el que vendrá a determinar la indisolubilidad entre violencia y ley, lazo que Benjamin calificará como mítico, es decir, por fuera del alcance de los hombres, absolutamente determinado e incuestionable en su validez, o en otros términos, ajeno al juicio de la razón y al análisis de sus compromisos históricos.

Para Benjamin, la violencia mítica es en definitiva una manifestación de la voluntad divina, voluntad que no solo opera en el momento fundante de la ley, sino que se perpetúa en el espíritu mismo del derecho, lo que resulta coincidente con los efectos de la lógica totémica según la perspectiva freudiana, dado que para esta última es a través de la propia ley -el interdicto totémicoque la violencia originaria se continúa propalando; aún más, la figura psíquica en que se encarna la función de la ley, el superyó, es pensada por Freud mucho más como una instancia sádica, por medio de la cual la violencia se manifiesta y satisface, que como una fuente de regulación y pacificación del conflicto psíquico. Pero lo fundamental de la operación psíquica por medio de la que el superyó se pone en acto no es simplemente que exprese un mandato moral que perpetúa la violencia, sino que tiene la estructura de un imperativo, es decir, de una orden impuesta desde afuera, desde un afuera radical y al mismo tiempo íntimo -la voz de la consciencia hace escuchar "desde adentro" un mandato que proviene "desde afuera". Para Lacan el imperativo superyoico proviene desde el Otro "pues de manera latente el imperativo moral no lo hace menos, puesto que es desde el Otro desde donde su mandato nos requiere" (LACAN, 2009a, p. 732); esta exterioridad del imperativo, que Lacan relaciona con la disyunción entre el sujeto del enunciado y el sujeto de la enunciación, ubica el lugar de producción de la máxima moral en un lugar de pura alteridad, exterioridad a la cual el sujeto se somete de manera equiparable a la forma en que la lógica mítica se impone a la ley, es decir, nublando la contingencia de su origen, lo que la hace aparecer como un principio de legitimidad ineludible o mítico. Sabemos que para Lacan el espacio de articulación significante en que la ley encuentra su soporte es una estructura caracterizada por su incompletud 
(LE GAUFEY, 2012), no obstante, el sujeto se confronta al imperativo como si este fuese un mandato incondicional al cual debe someterse, en una lógica que Freud (1996) no dejó de hacer equivaler a la relación del hombre con dios. Develar la estructura ficcional de la ley, en otros términos, la construcción fantasmática de su soporte mítico, parece ser la vía que permite efectuar una crítica al enlace aparentemente indisoluble entre violencia y ley; Benjamin trazó esta vía en su ensayo, queda por ver si es factible replicar este gesto como parte de una crítica psicoanalítica de la violencia.

La crítica de Benjamin no pretende sentar las bases de un proyecto que busque la total exclusión de la violencia en su relación al derecho, es decir, no imagina una ley que se ha purgado de toda violencia, sino que su crítica se dirige a concebir una violencia pura capaz de oponerse y detener el curso de la violencia mítica. No se trata entonces de librar a la ley de la violencia, sino de resistir la tentación de clausura que proporciona el mito, un cierre en el cual el carácter eminentemente antropológico de este último es curiosamente anulado por el recurso a una naturalización de la vida que es el efecto de la comprensión mítica de lo viviente. Benjamin utiliza una retórica de la sangre para dar cuenta de la construcción jurídica de la vida desnuda, una forma de vida que es siempre ya culpable por efecto de la retroactividad del mito, en tanto es ubicada como el principio de la caída del viviente humano:

La resolución de la violencia mítica se remite, y no podemos aquí describirlo de forma más exacta, a la culpabilización de la mera vida natural que pone al inocente e infeliz viviente en manos de la expiación para purgar esa culpa, y que a la vez, redime al culpable, no de una culpa, sino del derecho. (BENJAMIN, 1998, p. 41-42).

El mito es capaz de efectuar una torsión de la significación de la vida humana, ya que allí donde se esperaría que la vida sea cualificada como efecto de una construcción antropológica como lo es el mito, esta es producida como desnuda vida natural. La violencia de la expiación sacrificial se fundamenta en el precepto mítico que califica a la vida desnuda como portadora de una culpa originaria; pero esta no es la única consecuencia que se cierne sobre el viviente humano, ya que la vida desnuda no es solo culpable por su mera existencia, sino que además es excluida del ámbito de imperio de la ley. La violencia mítica resulta entonces el fundamento para la producción indefinida del estado de excepción (AGAMBEN, 2006), en tanto hace culpable a la vida desnuda por el solo hecho de tener lugar, al tiempo que la priva de acceso 
al derecho. Como antes indicáramos, la excepción tiene la estructura lógica de una exclusión inclusiva, un procedimiento a través del cual es incluido aquello que fue expulsado. Esta exclusión incluyente opera como el trasfondo oculto y negado de la ley, es decir, el caso particular, al que se supone una condición excepcional, y al que por tal razón se lo hace aparecer como externo al funcionamiento jurídico habitual, se encuentra inscrito en el corazón de la ley general. En este sentido podemos entender la siguiente afirmación de Agamben (1998, p. 34):

La ley presupone lo no jurídico (por ejemplo, la mera violencia en cuanto estado de naturaleza) como aquello con lo que se mantiene en relación potencial en el estado de excepción. La excepción soberana (como zona de indiferencia entre naturaleza y derecho) es la presuposición de la referencia jurídica en la forma de la suspensión.

En el estado de excepción la vida es simultáneamente incluida en el orden jurídico y arrojada a un umbral de indeterminación en el que carece de todo estatuto legal capaz de identificarle, con lo que, consecuentemente, resulta ajena a cualquier posibilidad de ser sujeto de derecho. Su desnudez es la total ausencia de un ropaje jurídico que pudiera brindarle alguna denominación o alguna identificación como parte de la civitas, lo que la convierte en una vida totalmente concernida por el derecho que sobre ella gravita, pero que la indetermina al negarle cualquier calificación jurídica que la identifique y con la que pueda identificarse.

No se trata entonces de una crítica de la violencia como medio puro, sino de aquella violencia mítica que opera reduciendo lo humano a vida desnuda, violencia que se traduce en una doble condena, por una parte de culpabilidad originaria, y, por otro lado, en una exclusión del reconocimiento por parte de la ley. Para Benjamin a esta violencia habrá que oponer otra fuerza, una violencia divina o pura, la que hará equivaler a la violencia revolucionaria:

Si la violencia tiene asegurada la realidad también allende el derecho, como violencia pura e inmediata, resulta demostrado que es posible también la violencia revolucionaria, que es el nombre a asignar a la suprema manifestación de pura violencia por parte del hombre. (BENJAMIN, 1998, p. 44).

El problema que aquí se presenta es cómo interpretar hoy en día la alusión de Benjamin a una violencia revolucionaria, llamado extremadamente 
problemático si se analiza desde la perspectiva que la historia del siglo XX nos proporciona. Tal vez una posibilidad de establecer un límite a la violencia mítica derive de pensar el problema de la exclusión de la ley de la que es objeto la nuda vida, cuestión que Benjamin esboza hacia el final de su ensayo cuando aborda la problemática ambigüedad de la sacralidad de la vida.

Como ha indicado Agamben (2006), la excepcionalidad de la ley que comporta el paradigma de la vida sacra, vuelve indiscernible la ley de la vida, haciendo de una la equivalente de la otra. El desafío es entonces encontrar una forma de minar la relación de exclusión inclusiva de la ley sobre la nuda vida por medio de una nueva forma de relación entre la vida y la ley, transformación que supone una re-cualificación de la forma de vida humana. La incógnita a descifrar es qué podría entenderse por una re-cualificación de la vida y de qué forma esta depende de una transformación de la ley.

En una carta dirigida a Gershom Scholem, fechada el 11 de agosto de 1934 (BENJAMIN; SCHOLEM, 2011), Benjamin refiriéndose a la obra de Kafka, y en particular a El castillo, señala que una pérdida de la clave para descifrar la Escritura hace que esta ya no sea escritura sino vida, vida "tal y como es vivida en el pueblo cercano al castillo" (BENJAMIN; SCHOLEM, 2011, p. 139), es decir, sujeta al absurdo de una ley tan omnipresente como incomprensible. Si la ley encuentra su suporte en la escritura, de la cual depende tanto su entrada en vigencia como su conservación, no debe perderse de vista que una ley que es fundada por la fuerza de la violencia mítica no puede ser completamente inteligible, ya que su punto de referencialidad es la fatal voluntad del destino. La vida desnuda, la vida en el pueblo al pie del castillo, se ausenta de la inteligibilidad en la medida de que está comprendida por la inescrutable escritura de una ley sostenida en la certeza mítica; la ley podría desembarazarse de la violencia mítica si pudiera expresarse como una nueva escritura, una escritura fundada en la vida cualificada, y ya no en el insondable destino mítico:

A la impermeabilidad de una escritura que, convertida en indescifrable, se presenta ahora como vida, corresponde la absoluta inteligibilidad de una vida enteramente resuelta en escritura. Sólo entonces los dos términos, que la relación de bando distinguía y mantenía unidos (la nuda vida y la forma de ley), se eliminan recíprocamente y entran en una nueva dimensión. (AGAMBEN, 2006, p. 75). 
Para Benjamin, el trabajo literario de Kafka resulta particularmente significativo, ya que en él se haría presente un intento de transformar la vida en escritura. Según Martel (2014), Kafka le entregó a Benjamin una forma de mesianismo textual que subvierte los poderes divinos y políticos que condicionan a los personajes de sus novelas, lo que haría de El castillo una parábola de aquello que Benjamín denomina "violencia divina", una forma de violencia que anula o destruye sus propios símbolos de poder, sus propias mitologías, lo que en términos políticos podría traducirse como un acto que viene a perturbar las narrativas de autoridad centrales a las que una comunidad se apega según la lógica de un mito incuestionable.

A partir de la idea de Benjamin de una vida que puede presentarse como una escritura inteligible, es decir, una escritura de la ley capaz de trastornar la violencia mítica a través de la anulación de los signos fatales del destino, podemos preguntarnos sobre la posibilidad de encontrar una alternativa de esta naturaleza dentro de los márgenes del psicoanálisis, propósito que nos hemos trazado para intentar sostener una crítica de la relación entre violencia y ley en psicoanálisis. A continuación intentaremos mostrar una vía de cuestionamiento a la connivencia de ley y violencia en la teoría psicoanalítica a través del análisis de la figura de Antígona, tomando como base la propuesta interpretativa desarrollada por Lacan en su seminario 7.

\section{Para concluir: Antígona, más allá de la Átē familiar}

No profundizaremos aquí en el problema de una ética del deseo tal como es presentada por Lacan en su seminario 7 (LACAN, 2007), ya que se trata de un argumento bien conocido y ampliamente comentado, sobre todo en el terreno de la filosofía política contemporánea que utiliza nociones psicoanalíticas para sostener sus propuestas (COPJEC, 2006; STAVRAKAKIS, 2003, 2007, 2010; ŽIŽEK, 1998, 2007; ZUPANČIČ, 2000). Del análisis de Lacan sobre Antígona destacaremos en particular la forma en que este sitúa la transgresión de Antígona respecto de la ley, interpretación en la que apostamos a encontrar un punto de confluencia con la noción de violencia divina benjaminiana.

La violencia divina es caracterizada por Benjamin como fulmínea, palabra cuya semántica alude a aquello que tiene la propiedad del rayo, y que viene a señalar las consecuencias que su advenimiento tiene respecto del orden previo. La violencia divina actúa borrando los rastros de la violencia 
mítica, pero sin derramar sangre, actuando con el fulgor incandescente de una potencia mortal pero incruenta, purificadora en lugar de sanguinaria. En el análisis de Lacan sobre Antígona podemos apreciar una confluencia significante en torno a la cuestión del brillo, palabra que resulta central en el retrato de Antígona esbozado por Lacan. El resplandor de Antígona -a la que Lacan no deja de calificar como inflexible, sin temor ni piedad, pero de una letalidad no sangrienta-, parece compartir el carácter fulmíneo de la violencia divina.

Más allá de la pura similitud terminológica entre la representación fulmínea de la violencia divina y el brillo de Antígona, lo que buscamos resaltar es la referencialidad de ambos campos semánticos a una concepción compartida de la transgresión/suspensión de la ley. La semántica del brillo es utilizada por Lacan para referirse al atravesamiento de cierto umbral por parte de Antígona, un límite que parece corresponder al franqueamiento de las dos formas de la ley que enmarcan la tragedia: las leyes de la ciudad y las leyes de los dioses. La interpretación de Lacan se distancia del comentario de Hegel (1985) sobre Antígona en Fenomenología del espiritu, ya que para Hegel el acto de Antígona solo transgrediría las leyes de la ciudad, en tanto se apega de forma absoluta e inmoderada a las leyes de la familia y los dioses. Lacan difiere de Hegel, ya que distingue en Antígona la transgresión de dos formas de la ley, en primer lugar las leyes del estado al oponerse al edicto de Creonte, punto en el que coincide con Hegel, pero también, lo que resulta menos obvio, las leyes de los dioses y la familia. Este último punto es desarrollado con detalle por Lacan, ya que supone sostener un argumento contraintuitivo, en la medida de que el reclamo de Antígona parece guiado fundamentalmente por su intención de cumplir a toda costa con los ritos fúnebres de su hermano, lo que haría patente su apego a los dioses según la interpretación de Hegel; para resolver el aparente impasse de su argumento, Lacan hará gravitar su análisis en torno al concepto de Átē, término que le permitirá situar el doble carácter de la transgresión de Antígona.

Según el conocido diccionario de mitología clásica de Grimal (1990), Átē es el nombre de la diosa de las acciones precipitadas, una personificación de las ilusiones y los engańos que aquejan a los humanos, ${ }^{2}$ por lo que se trata

${ }^{2}$ Átē y hamartia resultan términos aparentemente cercanos en los textos trágicos, no obstante deben ser claramente diferenciados, ya que hamartia alude fundamentalmente a una forma de error que "pertenece, inherente y exclusivamente, al carácter y pensamiento del propio héroe trágico." (GOLDEN, 1978, p. 12). Golden (1978), analiza una serie de textos de helenistas y filólogos contemporáneos para establecer los criterios diferenciales en el uso de los conceptos Átē y hamartia en la tragedia griega 
de un término que hace referencia a la injerencia hostil de los dioses en los asuntos terrenales y al ineluctable destino que esto implica para los humanos. La particularidad de la interpretación de Lacan estriba en que le atribuye a Antígona no solo una perseverancia en el cumplimiento de las leyes divinas, sino una transgresión de la Átē, es decir, un ir más allá de la fatalidad impuesta por los dioses.

El más allá de la Atē al que apunta el deseo de Antígona es para Lacan una trasposición del destino familiar al que se encuentra atada toda la descendencia de Edipo: "Uno se acerca o no a Átē y cuando uno se acerca a ella eso se debe a algo que, en este caso, está vinculado con un comienzo y con una cadena, la de la desgracia de la familia de los Labdácidas" (LACAN, 2007, p. 316), pero más adelante Lacan señala hacia donde se ve dirigida Antígona en su aproximación a la Áte familiar: "Ektòs es un afuera, lo que sucede una vez atravesado el límite de la Áte. [...] Ektòs átas tiene en el texto el sentido del atravesamiento de un límite y es efectivamente en torno a esto que se desarrolla en ese momento el canto del Coro." (LACAN, 2007, p. 324325). El franqueamiento del límite de la Átē es interpretado por Lacan como un sobrepasar los límites de toda forma de ley: "Pasar más allá, nómos, de las leyes. Ya no son más las leyes, nómos, sino cierta legalidad, consecuencia de las leyes ágrapta -traducido siempre por no escritas, porque eso es efectivamente lo que quiere decir- de los dioses." (LACAN, 2007, p. 334). Las palabras de Lacan dejan en claro su posición respecto de Antígona, ella ha sobrepasado todas las formas de la ley, tanto las de los hombres como las de los dioses. Este franqueamiento de la ley, al que Lacan califica como un atravesamiento de los límites del Otro, puede ser interpretado en un doble sentido, por una parte un ir más allá del orden simbólico y de la articulación significante, ese más allá del nómos al que alude Lacan, y también una transgresión del destino, la fatalidad divina que pesa sobre su estirpe. Para Lacan Antígona queda ubicada entre-dos-muertes, en un umbral de indeterminación que no es solo el límite entre la vida orgánica y su extinción en tanto viviente, sino el terreno liminar entre las leyes de la ciudad y el destino dictado por los dioses.

clásica. En particular, cuestiona la propuesta de Dawe (1968), quien plantea vincular ambos términos para la comprensión de la historia de Edipo en concordancia con las ideas de Aristóteles respecto de una tragedia ideal. Para Golden Átē y hamartia no resultan términos linealmente emparentados como propone Dawe, ya que el primero refiere a la influencia de los dioses sobre la vida humana, en tanto el segundo apela a las consecuencias sobre el destino de conductas que derivan exclusivamente de la voluntad del hombre. 
El momento de franqueamiento de este límite es caracterizado por Lacan como un momento de violenta iluminación, de belleza resplandeciente y mortífera, cuyo fulgor tiene un efecto enceguecedor que produce una detención de todo juicio: "El lado conmovedor de la belleza hace vacilar todo juicio crítico, detiene el análisis, y sumerge las diferentes formas en juego en cierta confusión o más bien en una ceguera esencial." (LACAN, 2007, p. 337). El brillo de Antígona opera una interrupción en el ciclo de las leyes a las que Antígona interpela en su acto; tal como la violencia pura, la transgresión de Antígona destituye el origen y los límites de la ley en curso, es decir, suspende la referencia mítica a un destino originario de la ley, en tanto se sobrepone a la Átē y bloquea la vigencia conservadora del nómos estatal al que se aferra Creonte.

El acto de Antígona escapa a la aprehensión imaginaria (la ceguera a la que Lacan alude) en la medida de que encarna la pulsión de muerte, lo que supone una salida de los límites que hacen inteligible el origen y soporte de las leyes, en otras palabras, se trata de un momento de franqueamiento de las formas y capacidad de representación que permiten articular toda forma de ley, sean estas las de la familia o las de la ciudad. El brillo de Antígona, su fulmínea violencia pura, indica el momento de suspensión de la ley, el hiato de indeterminación tanto de los orígenes como de la conservación de las formas de ley que ella desafía. En este punto resulta esclarecedor el carácter que Lacan le atribuye a la pulsión de muerte, concepto que considera fundamental, pero del que hace una interpretación que lo ubica en la vereda opuesta del biologicismo que resulta inherente al término en su versión original ${ }^{3}$. Lacan se distancia de la metabiología freudiana de la pulsión de muerte al comprender su tendencia compulsiva como una expresión de la relación que mantiene con la palabra; en tal sentido, para Lacan el más allá del principio de placer es la expresión de la insistencia del significante propia del orden simbólico (LACAN, 2008a, p. 309). Resulta paradójico que la pulsión de muerte sea considerada por Lacan como representante del orden simbólico, en tanto Freud la caracterizó por los efectos disolutivos de su operar, lo que parece precisamente oponerse al trabajo de ligadura significante característico del funcionamiento simbólico. En lugar de concebir la pulsión de muerte desde la perspectiva del retorno a lo inanimado de toda forma de vida orgánica, Lacan consideró la pulsión de muerte desde la perspectiva de la repetición, una insistencia cuya motivación califica de "prevital y transbiológica" (LACAN, 2009, p. 61) para dejar en claro

${ }^{3}$ Para una aproximación más detallada a la idea de un retorno de Freud a la biología a través de la teoría de la pulsión de muerte se recomienda al lector el texto El extravio biologizante de la sexualidad en Freud (LAPLANCHE, 1998), en especial entre las páginas128 a 135. 
de que esta no descansa sino sobre un basamento simbólico al que el sujeto se ve impelido tras caer en el "desfiladero radical de la palabra." (LACAN, 2009, p. 61). Debemos comprender entonces que para Lacan la compulsión a la repetición es la señal de la inercia del significante, una forma de retorno compulsivo que en lugar de promover la constitución de un tejido simbólico viene a exponer la falta estructural que la operación significante produce. La compulsión a la repetición es del orden de aquello que no cesa de no escribirse (LACAN, 2008b, p.114), es decir, la manifestación del vacío consustancial que la palabra abre en la realidad, la repetición de lo imposible de situar en lo simbólico y que es efecto de la propia aprehensión significante. El acto de Antígona atestigua de esa brecha, se orienta hacia ella, y en su persistencia es capaz de transgredir los límites de lo simbólico en la medida de que expone el exceso inasimilable que el propio orden simbólico ha generado y que ahora es imposible de reciclar en la cadena significante; las leyes, formas privilegiadas de articulación significante, no solo ya no recubren el acto de Antígona sino que se ven anuladas por este.

La pulsión de muerte es tratada por Lacan más desde una topología del significante que desde una semántica de la significación, en tanto señala que esta se ubica en los intervalos de la cadena significante. El espacio entre significantes, una brecha solo posible en la medida de que la experiencia es cernida por la palabra, da cuenta de ese vaciamiento que se le puede atribuir a la pulsión de muerte, pero desde una perspectiva en que esta es consecuencia de la introducción en la naturaleza de la organización significante. Lo que viene a insistir en toda articulación significante es del orden del hiato, una desligadura estructural que se hace presente en todo encadenamiento significante. Pero es también esta topología del vacío aquello que le confiere una paradójica productividad, ya que es la circulación de la significación alrededor del intervalo estructural que se abre entre los significantes lo que hace de la pulsión de muerte una forma de "sublimación creacionista." (LACAN, 2003, p. 257).

La pulsión de muerte es concebida por Lacan como una figura aporística, ya que encarna la destructividad bajo la forma de la transgresión de los límites de lo simbólico, pero simultáneamente es el principio de la propia productividad significante: "La producción es un dominio original, un dominio de creación ex nibilo, en la medida en que introduce en el mundo natural la organización del significante." (LACAN, 2003, p. 259). Si el acto de Antígona ha de ser pensado en la dimensión de la pulsión de muerte, debe deducirse que su brillo fulminante demarca tanto un punto de contravención 
de la ley como también de producción de una nueva opción para esta, en la medida de que reintroduce la función del significante - de la palabraallí donde las leyes vigentes reducen al sujeto a su pura condición de vida desnuda, es decir, desprovista de toda representación simbólica. La tragedia no expone el solipsismo autodestructivo de Antígona, esa pequeña fascista según el retrato de Anouilh (2009), sino el acontecimiento de una violencia pura capaz de interrumpir la forma de ley que hace de la vida una experiencia orgánica desnuda y arrojada fuera del derecho. Antígona atraviesa el umbral tanto de las leyes del estado que la condenan a muerte, como de la Áté familiar en que se inscribe la extinción de los labdácidas. Allí donde la violencia mítica culpabiliza y exige sacrificios, la violencia pura redime y acepta el sacrificio (BENJAMIN, 1998, p. 41-42), y es esta la dirección en que Antígona se orienta, hacia un más allá del deseo de violencia que se expresa en el mito. El deseo puro de Antígona, su encarnación del carácter creacionista de la pulsión de muerte, viene a abrir un espacio de re-fundación de la ley que interrumpe el ciclo conservador de la violencia mítica, en tanto su transgresión de las leyes es una interpretación en acto del deseo que sostiene a la polis y a su familia, y, como interpretación lograda, desmonta la fantasía fundamental en que se sostiene un deseo de violencia disfrazado de destino insondable.

CABRERA, J. P. For a critique of violence in psychoanalysis: from the original violence of the law to its tragic processing. Trans/form/ação, Marília, v. 42, n. 1, p. 101-122, Jan./ Mar., 2019.

\begin{abstract}
AвSTRACT: For Freud, the relationship between violence and law seems inseparable, in that the establishment of the law depends on an inaugural violence (the murder of the father). However, instead of being limited to this initial moment, this inaugural violence continues active through the psychic mechanisms which embody the function of the law, so that the law is constantly in collusion with the same violence that it tries to regulate. We think that this dilemma is equivalent to that defined by Benjamin in his Critique of Violence, an essay in which he proposes, through the figure of divine or pure violence, a way to interrupt the founding and conservative role of law attributed to mythical violence. It is proposed that Lacan's interpretation of the act of Antigone as a transgression of Áte is akin to Benjamin's idea of overcoming the compromise between mythic violence and the law that adjudicates the occurrence of pure violence. Lacan thus provides a critique of violence, this time within the theoretical margins of psychoanalysis. In both cases it is possible consider something beyond the compromise between violence and law, allowing one to think of a refoundation of the symbolic limits that support the law and regulate the bonds of community life.
\end{abstract}

KeYwords: Law. Critique of violence. Benjamin. Psychoanalysis. Antigone. 


\section{REFERENCIAS}

AGAMBEN, G. Homo sacer: el poder soberano y la nuda vida I. España: Pre-Textos, 2006. ANOUILH, J. Jezabel, Antígona. Buenos Aires: Losada, 2009.

ASSOUN, P.-L. Freud y las ciencias sociales: psicoanálisis y teoría de la cultura. Barcelona: Ediciones del Serbal, 2003.

BENJAMIN, W. Para una crítica de la violencia. In: Para una crítica de la violencia y otros ensayos. Iluminaciones IV. España: Taurus, 1998. p. 23-45.

. ; SCHOLEM, G. Correspondencia, 1933-1940. España: Editorial Trotta, 2011.

BOBBIO, N. El problema del positivismo jurídico. México: Fontamara, 1992.

CASTRO, E. Giorgio Agamben: una arqueología de la potencia. Buenos Aires: UNSAM EDITA, 2008.

COPJEC, J. Imaginemos que la mujer no existe: ética y sublimación. Buenos Aires: Fondo de Cultura Económica, 2006.

FREUD, S. Acciones obsesivas y prácticas religiosas. In: . Obras completas: volumen IX (1906-08): el delirio y los sueńos en la «Gradiva» de W. Jensen y otras obras. Buenos Aires: Amorrortu, 1989. p. 97-109.

. El malestar en la cultura. In: Obras completas: volumen XXI (192731): el porvenir de una ilusión, el malestar en la cultura y otras obras. Buenos Aires: Amorrortu: 1990. p. 57-140.

. Recordar, repetir y reelaborar: nuevos consejos sobre la técnica del psicoanálisis, II. In: Obras completas: volumen XII (1911-13): sobre un caso de paranoia descrito autobiográficamente, trabajos sobre técnica psicoanalítica y otras obras. Buenos Aires: Amorrortu, 1991a. p. 145-157.

. Tótem y tabú. In: . Obras completas: volumen XIII (1913-1914). Tótem y tabú y otras obras. Buenos Aires: Amorrortu, 1991b. p. 1-164.

. El problema económico del masoquismo. In: . Obras completas: volumen XIX (1923-25): el yo y el ello y otras obras. Buenos Aires: Amorrortu, 1992a. p. 161-176.

. El yo y el ello. In: Obras completas: volumen XIX (1923-25): el yo y el ello y otras obras. Buenos Aires: Amorrortu, 1992b. p. 1-66.

GRIMAL, P. A concise dictionary of classical mythology. Gran Bretańa: Basil Blackwell, 1990. HART, H. L. A. The Concept of Law. Oxford: Clarendon Press, 1994.

HEGEL, G. W. F. Fenomenología del espiritu. Madrid: Fondo de Cultura Económica, 1985. KELSEN, H. La teoría pura del derecho. México: Universidad Nacional Autónoma de México, 1979. 
LACAN, J. El seminario de Jacques Lacan: libro 7: la ética del psicoanálisis, 1959- 1960. Buenos Aires: Paidós, 2007.

- El seminario de Jacques Lacan: libro 2: el yo en la teoría de Freud y en la teoría psicoanalítica. Argentina: Paidós, 2008a. . El seminario de Jacques Lacan: libro 20: aún. Argentina: Paidós, 2008b.

. Kant con Sade. In: Escritos 2. México: Siglo XXI, 2009a. p. 727-751. p. 23-69.

. El seminario sobre la carta robada. In: Escritos 1. México: Siglo XXI, 2009b.

. El seminario de Jacques Lacan: libro 11: los cuatro conceptos fundamentales del psicoanálisis. Argentina: Paidós, 2010.

. Proposición del 9 de octubre de 1967 sobre el psicoanalista de la Escuela. In: Otros escritos. Buenos Aires: Paidós, 2012. p. 261-277.

LAPLANCHE, J. El extravio biologizante de la sexualidad en Freud. Buenos Aires: Amorrortu, 1998.

LE GAUFEY, G. La incompletud de lo simbólico. Buenos Aires: Ediciones Lecol, 2012. LÉVI-STRAUSS, C. Las estructuras elementales del parentesco. Barcelona: Paidós, 1998. MARTEL, J. Textual conspiracies, Walter Benjamin, idolatry, and political theory. Estados Unidos de América: The University of Michigan Press, 2014.

STAVRAKAKIS, Y. The lure of Antigone: aporias of an ethics of the political. $\operatorname{Umbr}(a): A$ Journal of the Unconscious (Ignorance of the Law), n. 1, p. 117-129, 2003.

. Lacan y lo político. Buenos Aires: Prometeo Libros, 2007.

. La izquierda lacaniana: psicoanálisis, teoría, política. Argentina: Fondo de Cultura Económica, 2010.

ŽIŽEK, S. From "passionate attachments” to dis-identification. Umbr(a): A Journal of the Unconscious, (Identity / Identification), n. 1, p. 3-17, 1998.

Paidós, 2007.

. El espinoso sujeto: el centro ausente de la ontología política. Buenos Aires:

ZUPANČIČ, A. Ethics of the real: Kant, Lacan. Londres: Verso, 2000.

Recebido: $16 / 10 / 2017$

Aceito: $29 / 11 / 2018$ 
CABRERA, J. P. 